\title{
A Study on the Antimicrobial Finishing of Rodalon on Silken Carpet
}

\author{
Ali Ashjaran ${ }^{1,}$, Reza Ghazi-Saeidi ${ }^{2}$, Abusaeid Rashidi $^{3}$, Ramin Khajavi $^{4}$ \\ ${ }^{1}$ Department of Textile, Islamic Azad University, Shahre rey Branch-Tehran-Iran \\ ${ }^{2}$ Department of Textile, Islamic Azad University, South of Tehran Branch-Tehran-Iran \\ ${ }^{3}$ Department of Textile, Islamic Azad University, Science and Research Branch-Tehran-Iran \\ ${ }^{4}$ Department of Textile, Islamic Azad University, South of Tehran Branch -Tehran-Iran
}

\begin{abstract}
In Iranian culture, carpet is the first choice for covering the floor; it is a very suitable substrate for growing pathogenic microbes. In this research, the main aim is to investigate the antibacterial effectiveness of rodalon solutions on silken fibers by spraying method used in silken carpet. Silken pile carpet laid in a public place (in VIP of The Homa hotel) for 30 days and some microbes found on them were investigated . The antimicrobial effect of different Rodalon solutions on the identified microbes was studied in vitro. The silken fibers were treated with solutions of Rodalon like before and the antimicrobial effectiveness was assessed by the zone of inhibition method at different times. Two pieces of carpet untreated and treated with Rodalon solution were sewed together and laid for two weeks in a public place and the amounts of bacterial growth on it was determined by colony count method and the results were compared. Finally some mechanical properties of treated silken fibers were measured after 30 days and was compared with untreated one. The results showed the presence of some pathogenic microbes on the laid carpet such as Escherichia coli and Staphylococcus aureus. The inhalation time for treated silken fibers was found to be improved. The amount of colony growth on treated carpet reduced considerably and moreover the mechanical test results showed no significant deterioration effect of studied properties in comparison to the untreated yarn.
\end{abstract}

Keywords: Rodalon, silken carpet, inhalation time, colony count, escherichia coli, staphylococcus aurous.

\section{Introduction}

Micro organism is a part of our life. Activities of microorganisms on the textile products will result in three major problems: risk human health, produce bad odour and finally destruction of good [1,2]. Carpet is a famous textile, it is a very suitable substrate for growth of microorganisms such as pathogenic microbes, due to direct contact with human body, long washing periods and laying on the floor [3-5].

The silken carpet in comparison with other carpets has a special position, for this reason it needs some special methods to maintain the quality of these goods, and protect from the action of microorganisms. In the recent years, for prevention from the action and transition of harmful microbes many researches (be a complied) on antimicrobial material with short and long term effects in production, construction and completion of fibers [6,7]. It is very important to pay attention to the health and cleanliness part of it. Mentioned, two different aspects of antimicrobial protection provided by chemical finishes can be defined. The first is the protection of the textile user against pathogenic or odour causing microorganisms
(Hygiene finishes). The second aspect is the protection of the textile itself from damage caused by mould, mildew or rot producing microorganisms that it can be called antibacterial protection finish. According to Schindler and Hauser (2004) and Vigo (1997) many agents including inorganic salts, organometallics, iodophors (substances that slowly release iodine), phenols and thiophenols, onium salts, antibiotics, heterocyclics with anionic groups, nitro compounds, urea and related compounds, formaldehyde derivatives, biopolymers and amines have been used as antibacterial agent for hygiene finish or antibacterial protection finish. There are many studies in this field using these compounds [3,610].

Many antimicrobial agents have been used as antimicrobial agent for hygiene finish or antibacterial protection finish [11,12]. Between these antimicrobial agents quaternary ammonium salts exhibit marked antibacterial activity against a wide range of bacteria. These compounds have a central nitrogen atom which is joined by four organic radicals and one acid radical. Quaternary ammonium halide cationic surfactants are widely used for antibacterial surface-active and detergent properties [13-17]. 
Rodalon shown in Fig. 1 is one of the conventional quaternary ammonium salts. Its solutions are rapidly actas anti-infective agents with a moderately long duration of action. They are active against bacteria, some viruses, fungi and protozoa. Solutions are bacteriostatic or bactericidal according to their concentration $[3,4]$.

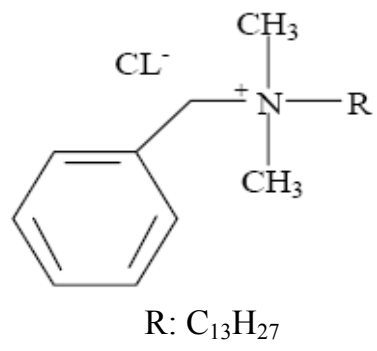

Figure 1 Molecular structure of Rodalon.

The exact mechanism of bacterial action is unknown but it is thought to be due to enzyme inactivation. Activity generally increases with increasing temperature and $\mathrm{PH}$. It has been used in textile industry, as an insecticidal, or antimicrobial $[4,18,19]$ agent.

In this study a conventional antiseptic agent, Rodalon (e.g. Roda) was applied through spraying method for improving silken carpet's inhibition against some pathogenic microbes and the antibacterial effectiveness of the carpet was evaluated by standard test methods.

\section{Material and Methods}

\subsection{Material}

Rodalon was purchased from Asalib Co. (Table 1). The carpets were purchased from Saran Co. (Table 2). Silken yarns were prepared from Saran Co. (8/2 Nm). The pure bacteria were supplied by the Bouali Hospital, Tehran, Iran and all tests were done in the Laboratories of Tarbiat modarres University, Islamic Azad University Science and Research Campus Branch and Islamic Azad University of Shahre-Rey in 2008.
Table 1 Technical data of the applied Rodalon

\begin{tabular}{cc}
\hline Trade name & Rodalon 50 \\
\hline Product & $\begin{array}{c}\text { A 50\%v/v solution of alkal } \\
\text { benzyl dimethyl ammonium } \\
\text { chloride, complying with BP2003 } \\
\text { and USP 26-NK 21 monograph. }\end{array}$ \\
Appearance $20^{\circ} \mathrm{C}$ & Clear liquid \\
Color & Colorless to pale yellow \\
Density at $20^{\circ} \mathrm{C}$ & $0.99 \mathrm{G} . \mathrm{cm}^{-3}$ \\
Viscosity at $20^{\circ} \mathrm{C}$ & $120 \mathrm{CS}$ \\
Assay(mmw=349.8) & $50 \pm 1$ \\
Non-quaternished & $0.5 \% \mathrm{max}$ \\
amine(mmw=223.3) & $0.2 \% \mathrm{max}$ \\
Sulphated ash & $6.5-8.5$ \\
PH(5\% in water) &
\end{tabular}

Table 2 Specifications of the applied carpets

\begin{tabular}{cc}
\hline Color & Ivory(mostly) \\
\hline Pile yarn & $100 \%$ silk \\
Pile length & $11 \pm 1 \mathrm{~mm}$ \\
warp yarn & $100 \%$ silk \\
weft yarn & Cotton $/$ Polyester $(35 / 65) \%$ \\
\hline
\end{tabular}

\subsection{Methods}

For investigating the kind of bacteria present on carpet, (especially pathogenic ones) carpets were laid in a public place (in VIP of the Homa Hotel) for 30 days (everyday approximately 300 people had stepped on it), thereafter some fibers were cut from the carpets randomly and immersed in Thioglycolate and Nutrient broth mediums. After incubating for $24 \mathrm{hrs}$ at $37^{\circ} \mathrm{C}$, the solutions of each media were sub-cultured in Nutrient and Blood agar mediums and after incubating in Nutrient and Blood agar mediums for $48 \mathrm{hrs}$ at $37^{\circ} \mathrm{C}$ the colonies of microbes were cultured by streak test method. For identifying the kind of cultured microbes the gram stain, catalase, oxidase, citrate agar, Christensen's urea broth and TSI agar tests were done. The cultured microbes were kept in skimmed milk as the next step. Ditch plates method was used for evaluating the antibacterial effectiveness of Rodalon against the detected bacteria on the carpet. Ditch plates were prepared by allowing the Mueller Hinton Agar to solidify in a Petri dish and ditches (with diameter of approximately $4 \mathrm{~mm}$ ) produced on it by removing the agar. Ditches were inoculated by different Rodalon solutions (1/100, 1/500, 1/1000 and $1 / 2000 \mathrm{v} / \mathrm{v}$ solutions of Rodalon). 
The dishes were incubated for $18 \mathrm{hrs}$ at $37^{\circ} \mathrm{C}$ to let the Rodalon solutions penetrate into the agar medium. Microbes (stored in skim milk) were mixed with a semi liquid Mueller Hinton Agar (Agar conc. <1\%) and added to the inoculated plates. The plates were incubated at $37^{\circ} \mathrm{C}$ and the zone of inhibition at different time intervals $(12,24,48,72,96,120,148$, 172, 196, 220, 244 and $268 \mathrm{hrs}$ ) were determined. The positive results were repeated three times and the mean of the zone of inhibition was reported for 120 hrs. Silken fibers were sprayed with in different solutions of Rodalon (1/100,1/500, 1/1000, 1 /2000 $\mathrm{v} / \mathrm{v}$ solutions of Rodalon) and after drying they entered in plates containing the pure microbes and the zone of inhibition was observed until the zone of inhibition disappeared. Every 24 hrs the plates were replaced with new plates of pure Microbes. For comparing the antibacterial effectiveness of Rodalon in practice one carpet was split into two parts, one remained untreated and the other treated with Rodalon solution $(1 / 500 \mathrm{v} / \mathrm{v}$ solution of Rodalon by spraying method). Two pieces were sewed together and laid in public place ( in IVP of the Homa Hotel). Some fibers cut out of two samples and the previously described methods were use for culturing and separating the microbes and the antimicrobial effectiveness of Rodalon on carpet was measured by colony count method. Some mechanical properties of untreated and treated (1/500\% v/v solution of Rodalon) silken yarns were measured by Tensorapid (SDL Co.) after 30 days. The length for every sample was $300 \mathrm{~mm}$ and the speed of test was $999.9 \mathrm{~mm} / \mathrm{min}$.

\section{Results and Discussion}

The presence of some microbes were proved in the experimental carpet laid for 30 days, including Escherichia coli, Enterobacter, Staphylococcus aureus, Pseudomonas, Bacillus, Penicillum, Aspergillus, Fusarium, Mucor. Colonies of microbes are shown in Figs. 2 and 3.

The antimicrobial effectiveness of Rodalon solutions on the detected microbes after $120 \mathrm{hrs}$ is shown in Table 3. According to the results the $1 / 2000$ $\mathrm{v} / \mathrm{v}$ solution of Rodalon shows no significant antimicrobial effect.

Antibacterial effects of treated silken fibers with different solutions of Rodalon assessed for the remaining time in the zone of inhibition are shown in Table 4. Comparing results of the treated and untreated pieces of carpet after laying them for two weeks in a public place is shown in Table 5. It can be seen that the number of colonies growth were decreased about 56, 93, 97 and 90\% for Stapylococcus, Bacillus, Pseudomonas and Escherichia coli respectively.

The effect of $1 / 100 \mathrm{v} / \mathrm{v}$ solution of Rodalon on some mechanical properties of treated carpet in comparison with untreated one is shown in Table 6. There is no significant deterioration effect on the studied mechanical properties. (e.g. the significant level of $\alpha=0.05$, about Table 6).

Table 3 Antimicrobial effect of Rodalon solutions on the detected Microbes on the carpet

\begin{tabular}{ccccc}
\hline \multicolumn{5}{c}{ The zone of inhibition (mm)of Rodalon solution } \\
\hline Microbe & $1 / 100$ & $1 / 500$ & $1 / 1000$ & $1 / 2000$ \\
$(\mathrm{v} / \mathrm{v})$ & $(\mathrm{v} / \mathrm{v})$ & $(\mathrm{v} / \mathrm{v})$ & $(\mathrm{v} / \mathrm{v})$ \\
Escherichia coli & 18 & 14 & 12 & $*$ \\
Enterobacter & 17 & 14 & 12 & $*$ \\
Staphylococcus & 16 & 14 & $*$ & $*$ \\
Pseudomonas & 13 & 13 & $*$ & $*$ \\
Bacillus & 12 & Less than & $*$ & $*$ \\
Penicillum & 14 & 12 & $*$ & $*$ \\
Aspergillus & 14 & 12 & $*$ & $*$ \\
Fusarium & 14 & 12 & $*$ & $*$ \\
Mucor & 14 & 12 & $*$ & $*$ \\
\hline
\end{tabular}

*: Showed no zone of inhibition

Table 4 Antimicrobial effect of treated silken fibers with Rodalon

\begin{tabular}{ccccc}
\hline \multicolumn{5}{c}{ Maximum time of inhibition of treated fibers with } \\
Rodalon solution (hr) \\
\hline Microbe & $1 / 100$ & $1 / 500$ & $1 / 1000$ & $1 / 2000$ \\
& $(\mathrm{v} / \mathrm{v})$ & $(\mathrm{v} / \mathrm{v})$ & $(\mathrm{v} / \mathrm{v})$ & $(\mathrm{v} / \mathrm{v})$ \\
Escherichia coli & 263 & 161 & 67 & 29 \\
Enterobacter & 264 & 161 & 66 & 29 \\
Staphylococcus & 237 & 93 & 67 & 31 \\
Pseudomonas & 162 & 47 & 23 & $*$ \\
Bacillus & 42 & 24 & $*$ & $*$ \\
Penicillum & 243 & 75 & $*$ & $*$ \\
Aspergillus & 244 & 99 & $*$ & $*$ \\
Fusarium & 244 & 98 & $*$ & $*$ \\
Mucor & 219 & 75 & $*$ & $*$ \\
\hline
\end{tabular}

*: Showed no zone of inhibition

Table 5 Number of colonies growth on untreated and treated carpet with $1 / 100$ Rodalon ( $/ \mathrm{v}$ ) after 14 days

\begin{tabular}{ccc}
\hline & No.of colonies & \\
\cline { 2 - 3 } Bacteria & Untreated & Treated \\
& carpet & carpet \\
Staphylococcus & 9.4 & 6.2 \\
Bacillus & 101.98 & 9.4 \\
Paeudomonas & 19 & 2.5 \\
Escherichia coli & 21 & 1.5 \\
\hline
\end{tabular}


Table 6 Effect of treating silken yam with Rodalon on some mechanical properties after 30 days

\begin{tabular}{ccccc}
\hline $\begin{array}{c}\text { Mechanical Elongation } \\
\text { property }\end{array}$ & $\begin{array}{c}\text { Work of } \\
\text { rupture } \\
(\mathrm{N} . \mathrm{m})\end{array}$ & $\begin{array}{c}\text { Initial } \\
\text { modulus } \\
(\mathrm{cN} / \mathrm{Tex})\end{array}$ & $\begin{array}{c}\text { Tenacity } \\
(\mathrm{cN} / \mathrm{Tex})\end{array}$ \\
\hline Untreated & 6.232 & 5.9562 & 556.98 & 39.560 \\
CV & 8.984 & 12.3200 & 6.68 & 5.020 \\
Treated & 6.185 & 6.0120 & 561.50 & 39.732 \\
CV & 8.120 & 9.4900 & 2.92 & 2.456 \\
\hline
\end{tabular}
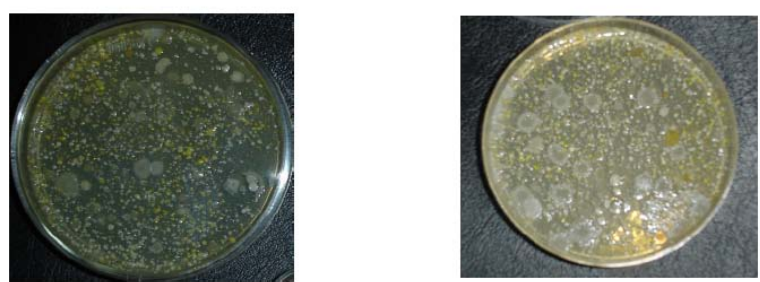

Figure 2 Colonies of microbes on Nutrient agar plate
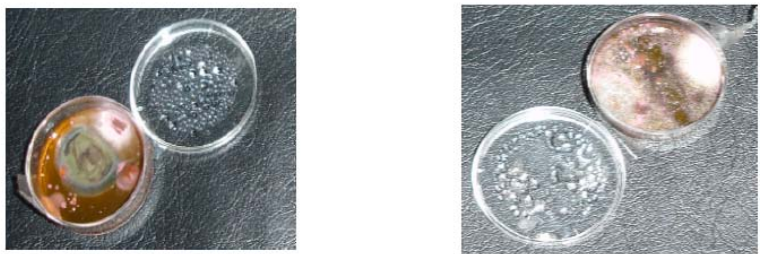

Figure 3 Colonies of microbes on blood agar plate

\section{Conclusions}

Rodalon was chosen for this study because it is a common antiseptic and it belongs to the group of cationic surface active agents. Considering its charge it can act as a link to a cationic dye and tend to take up and hold on the surface of natural substrate such as silk. According to the results the presence of some pathogenic microbes on the laid carpet confirmed including Escherichia coli and Staphylococcus which can be causing many infections. So it is worthy to enhance the antimicrobial activity of the carpet with a proper antimicrobial finishing. Although the kind of microbes on the carpet depends considerably on environment, but it was shown that treating silken fabric with Rodalon inhibits considerably the growth amount of studied bacteria and in some cases up to $99 \%$.

The wash fastness or durability of the effect against washing the treated carpet in this study was not given much attention because the interval between washing periods for textile floor coveris quite long and during these intervals usually the activity of the antibacterial agent vanishes, as in the case of Rodalon whose maximum inhibition time with a high concentration $(1 / 100 \mathrm{v} / \mathrm{v})$ was just $263 \mathrm{hrs}$.

\section{References:}

[1] Gupta D, Laho A. Antimicrobial activity of cotton fabric treated with Quercus extract. Indian J Fiber Textile Res 2007;32: 88-92.

[2] Lee HJ, Jeong SH. Bacteriostasis and skin innoxiousness of nanosize silver colloids on textile fabrics. Textile Res J 2005;75:551-556.

[3] Khajavi R, Satari M, Ashjaran A. The antimicrobial effect of benzalkonium chloride on some pathogenic microbes observed on fibers of acrylic carpet. Pakistan J Biological Sci 2007;10:598-601.

[4] Ashjaran A, et al.. Investigation of antibacterial effect of benzalip on some bacteria observed on acrylic carpet by spraying method. $86^{\text {th }}$ International Textiles Congress in Hong Kong. 2008. p. 27.

[5] White WC, McGee JB, Malek JR. New antimicrobial treatment for carpet applications. American Dyestuff Reporter, 2006.

[6] Nakashima T, Sakagami Y, Matsua M. Antibacterial activity of cellulose fabrics modified with metallic salts. Textile Res J 2001;71:688-694.

[7] Han S, Yang Y. Antimicrobial activity of wool fabric treated with curcumin. Dyes Pigment 2005;64:157-161.

[8] Anand SC, Kennedy JF, Miraftab M, Rajendran S. Medical textiles and biomaterial for healthcare. Woodhead publishing limited, Cambridge England. 2006. p. 177-186.

[9] Lim S, Hundson SM. Application of a fiber reactive chitosan derivative to cotton as an antimicrobial textile finish. Carbohydrate Polymers 2004;56:227-234.

[10] Young Ho, Chang Woo KN, Won CJ, Jinho J. Durable antimicrobial treatment of cotton fabrics using N-(2-hydroxy) propyl-3trimethylammonium chitosan chloride and polycarboxylic acids. Appl Polym Sci 2003;88:1567-1572.

[11] Schindler WD, Hauser PJ. Chemical finishing of textiles. Woodhead Publishing Limited. Cambridge England. 2004; p.165-174.

[12] Vigo TL. Textile processing and properties: preparation, dyeing, finishing and performance. Elsevier Science B.V, 1997.p.252-258. 
[13] Ashjaran A, et al. Investigation of presence some pathogenic micro organism on acrylic carpet. $3^{\text {rd }}$ - International Technical Textiles Congress. 2007. p.265-270.

[14] Shao H, Jiang L, Meng W, Qing F. Sunthesis and antimicrobial activity of a Perfloroalkylcontaining quaternary ammonium salt. J Fluorine Chem 2003;124:89-91.

[15] Huang R, Du Y, Zheng L, Liu H, Fan L. A new approach to chemically modified chitosan sulfates and study of their influences on the inhibition of Escerichia coli and Staphylococcus aureus growth. Reactive and Functional Polymers 2004;59:41-51.

[16] Tatsuo T, Masahiro I, Kyoji K, Yukio S. Synthesis and antibacterial activity of copolymers having a quaternary ammonium salt side group. J Appl Polym Sci 1989;37:2837-2843.
[17] Gloor M, Schorch B, Hoeffler U. The feasibility of replacing antibiotics by quaternary ammonium compounds in topical antimicrobial acne therapy. Arc Dermato Res 1979; 265:207-212.

[18] Bahgat MA, Falaha AEl, Russell AD, Furr JR, Rogers DT. Activity of Benzalkonium chloride and chlorhexidine diacetate against wild-type and envelope mutants of Escherichia Coli and Pseudomonas aeruginosa. Intl J Pharmaceutics 1985;25:327-329.

[19] Marple B, Roland P, Benninger M. Safety review of benzalkonium chloride used as a preservative in intranasal solutions: An overview of conflicting data and opinions. American Academy of Otolaryngology- Head and Neck Surgery Foundation. Inc. 2003. p.131-142. 